\title{
Contribution to the Newsletter
}

Hosting eBooks on our website has been introduced a few years ago and includes the EFSUMB Course Book on Ultrasound (ECB), among others which have also been published in a printed format and the online EFSUMB Course Book Student Edition (ECBSE) which has been launched at EUROSON 2013 in Stuttgart. The ECB has been published on the new Educational Portal (http://www.efsumb-portal.org/ ep). Additionally, examination technique videos are available [www.efsumb.org] [http://www.efsumb-portal.org/ep/category.php?id=152]. Most importantly, eBook information can be updated and this is important in what is one of the most rapidly advancing fields of medicine.

This multidisciplinary ECB is intended to complement and advance the educational purposes of EFSUMB in a modern way, and will integrate the extensive experience of European authors and ultrasound teachers into clinical courses, also providing accreditation. The ECB is aiming at illustrating and supporting the EFSUMB course system and the well established EUROSON Schools. In addition, the ECB incorporates the minimum training recommendations for the practice of medical ultrasound published by EFSUMB. Up to now 26 chapters have been introduced and are available online.

1. Chapter Introduction,

2. Chapter US of the Liver,

3. Chapter Estimation of Liver Stiffness,

4. Chapter Liver Transplantation,

5. Chapter US of the biliary system

6. Chapter Pancreas,

7. Chapter Transabdominal US of the gastrointestinal tract,

8. Chapter Functional US of the gastrointestinal 1 tract,

9. Chapter Genitourinary US,

10.Chapter US of the scrotum,

11. Chapter Nephrology, transplantation and shunts,
12.Chapter US of the adrenals

13.Chapter Thyroid US,

14.Chapter Sonography of the salivary glands and soft tissue lesions of the neck,

15.Chapter Chest sonography,

16. Chapter Introduction to US in vascular disease and introduction,

17.Chapter Doppler US of the aorta, inferior vena cava and visceral arteries,

18. Chapter Doppler US of renal vessels,

19.Chapter US of peripheral veins,

20.Chapter US evaluation of cerebrovascular obstructive diseases,

21.Chapter US in peripheral arterial disease,

22.Chapter Interventional US,

23.Chapter Technical Quality Evaluation of diagnostic US systems,

24.Chapter Sonopsychology,

25.Chapter US in tropical diseases,

26.Chapter US in tropical medicine. Human Immunodeficiency Virus (HIV) Infection

The course book is devoted to the interdisciplinary approach of the multinational societies of EFSUMB. Therefore, additional disciplines will be introduced in the near future. There are new chapters which are under preparation including an introduction into echocardiography, ultrasound of the musculoskeletal system, and endoscopic ultrasound.

As already mentioned, a version of the ECB should be made accessible for students, hence the ECBSE. EFSUMB is of the opinion that it is very important that medical students are trained in the principles of diagnostic ultrasound. Ultrasound can be a highly valuable tool not just in diagnostics but also in enabling students to understand anatomy and physiology. EF-
SUMB will promote a uniform education for all medical students. Therefore, compared to the ECB, the ECBSE offers less detail. Examination technique videos are necessary for students and the aim is to produce a version by 2014 considering these criteria. The first chapters of the ECBSE are already available on the EFSUMB website and an electronic version of the book is under consideration, such as a DVD, or USB stick or even an app so that the 'book' could be offered at the lowest possible price, be easily mailed to those who would like a permanent version and be easily transferable to congresses or educational institutions. Chapters that are already published, or almost ready, include examination technique, "knobology", liver, biliary tract, spleen, neck, pancreas, gastrointestinal tract, FAST, Echoscopy: Clinical investigation with US.

The ECB and ECBSE are hosted on the Educational Portal of the website under the icon ECB and ECBSE, respectively. Videos are embedded in the chapters with an additional first chapter ( $\mathrm{Ch}$ O0) listing the videos for quick reference to the procedure, without the need to search through the text. For bulk printed book purchases or for any further information please contact efsumb@efsumb.org

Dietrich CF, Gilja OH, Sidhu P, Schwarzenbach $H$, Piscaglia $F$

Corresponding author:

Prof. Dr. med. Christoph F. Dietrich EFSUMB President

Med. Klinik 2

Caritas-Krankenhaus Bad Mergentheim

Uhlandstr. 7

97980 Bad Mergentheim

Tel.: (+) $49-7931-58-2201$

Fax: (+) $49-7931-58-2290$

Email: christoph.dietrich@ckbm.de 